\title{
Comparison of SCAT-3 Baseline Testing and P300 ERP between Seasons in University Football Players
}

\author{
Dillon J. Richards ${ }^{1}$ \\ University of Western Ontario
}

\begin{abstract}
Contact sport teams require their athletes to undergo baseline concussion testing for comparison to their postconcussion results. The standard test during this study was the Sport Concussion Assessment Tool-3rd edition (SCAT-3). Clinically used for return to play procedure, most athletes return to baseline scores 8-10 days' post-concussion. Electroencephalography (EEG) is a non-invasive means of measuring the electro-physiological function of the brain. EEGs are the summative measure of EventRelated Potentials (ERPs) which are measures of brain activity after a specific event. P300 is an example of an ERP that is commonly used as a neurocognitive marker in concussion research. P300 can be further broken down into P3a and P3b, which relate to attention and decision making respectively. Using this technique, lasting functional deficits, beyond those that are highlighted on the SCAT-3 scores, have been noted. This study aims to evaluate the effect subconcussive impacts (SCI) have on SCAT-3 and electrophysiology from one season to the next in Canadian University football players over two seasons. Participants underwent standard SCAT-3 and EEG baseline testing at the beginning of two subsequent seasons. The EEG tests consist of two 5-minute baseline periods with eyes open and closed, followed by a 10-minute session collecting event-related potentials using a three-stimulus Oddball paradigm. Players mean scores showed increases in both number of symptoms $(1 \pm 4.08)$ and symptom severity $(1.9 \pm 6.6)$. Mean P3a and P3b latencies increased. Additionally, mean amplitudes decreased for both P3a and P3b. University Football players show physiological defects from accumulated SCl during a season. These deficits may accumulate each successive season without resolution. Due to their slow onset, evaluations of these changes are difficult identity. EEG measurements are sensitive to small changes in function and serve as an ideal tool to measure these changes. The SCAT- 3 is less sensitive to these minor changes but still has value since it can be used acutely in sideline assessment of concussion.
\end{abstract}

KEYWORDS: concussion, football, electroencephalography

\section{Introduction}

The purpose of this study was to investigate the effect of accumulated subconcussive impacts on University Football Players through physiological testing. Concussion is defined as a complex pathophysiological process affecting the brain, caused by biomechanical forces resulting from a direct or indirect blow to the head or body (1). An individual's symptom presentation following a concussion may vary depending on the force characteristics of the impact and the brain areas affected (2). These symptoms may be physical, cognitive, emotional, or sleep related (1). Acutely, $91 \%$ of athletes will have resolution of these symptoms within 7 days (3). This apparent quick resolution of symptoms has led to a common assumption that concussions have no lasting neurological deficits. However, research using Magnetic Resonance Imaging (MRI) and Electroencephalography (EEG) have found prolonged deficits beyond symptom resolution $(1,4-$ $8)$. This research has not defined a "threshold" for concussion causing impacts, however ranges with increased likelihood of concussion have been found (1). Literature has shown an average $9.3-\mathrm{m} / \mathrm{s}$ impact velocity, $7.2-\mathrm{m} / \mathrm{s}$ change in head velocity, and 961.05 $\mathrm{m} / \mathrm{s}^{2}$ head acceleration in professional football players (9).

Not all impacts will be of such magnitude, the majority of impacts that an athlete endures will not cause concussion. These sub-concussive impacts (SCl) are defined as any impact to the head causing mild brain trauma that does not result in observable concussion symptoms (10). American college football players receive roughly 3,500-28,000 SCls for every concussion (11). Recent studies found Canadian university players received an average of 335 impacts in a season (12). These impacts accumulate and may cause pathologies without symptom presentation. Using Diffusion Tensor Imaging MRI, Bazarian et al. observed changes in white matter tracks in the corpus callosum of collegiate football players six months after a season of play (5). These repetitive impacts have been related to development of chronic traumatic encephalopathy (CTE) later in life. (5-8) The Center for the Study of CTE states repetitive impacts are 
"necessary but not sufficient" for the development of CTE (13).

Assessing athletes for these symptoms has been difficult and has undergone numerous revisions. Currently, clinical best practice for assessment of concussion recommends incorporating neurocognitive assessment into diagnosis (1). The Sports Concussion Assessment Tool- $3^{\text {rd }}$ edition (SCAT-3) is a freely available standardized neurocognitive assessment. Both the National Football League (NFL) and National Hockey League (NHL) have used versions of the SCAT for sideline assessment of concussion (16). The SCAT3 assesses athletes using subtests such as; The Glasgow Coma Scale, Maddox Score, Standardized Assessment of Concussion (SAC) and modified Balance Error Scoring System (mBESS) (1). The SCAT-3 functions both as a baseline and immediate sideline measure. It is recommended that multiple test be completed by athletes' post-concussion, with these scores compared to an athlete's baseline $(14,15)$. The SCAT-3 represents an easy to administer and reliable assessment of concussion. However, it has been shown that some athletes purposely decrease performance to reduce the likelihood of their removal from games during later assessment (53). For this reason, clinicians are more reliant on physiologic responses to concussion that cannot be fabricated.

Electroencephalography (EEG) is a commonly used measure of physiological function. It measures the electrical fields generated in the brain that travel to the surface of the scalp. Which has proven useful for both research and clinical assessment of neurological deficits (18-20). EEG is tool that can detect subtle changes in brain function (21). It is non-invasive, portable and relatively inexpensive (22) allowing it to be incorporated in concussion assessment. EEGs measure the sum of all the Event-related brain potentials (ERPs) occurring at the time of measurement. ERPs represent voltage changes in neurons in response to a specific stimulus (23). ERPs are useful in providing insight to underlying cognitive function (23), and tracking changes in electrical function after concussion (24). However, these deficits are not always accompanied with presentation of symptoms $(25,26)$.

A specific ERP of interest in concussion research is the $\mathrm{P} 300$ wave. It is commonly divided into two subcomponents, $\mathrm{P} 3 \mathrm{a}$ and $\mathrm{P} 3 \mathrm{~b}$, which relate to attention and decision making respectively (27). The P300 occurs when an individual responds to a task relevant stimulus (28). The best known paradigm for producing the $\mathrm{P} 300$ is the Oddball paradigm. Two stimuli differing in characteristics (pitch of sounds or size of shape), one occurring frequently the other infrequently are presented to an individual. The individual must response to the infrequently occurring stimuli. The presentation of the frequent stimuli produces the P3a subcomponent which is thought to relate to stimulus recognition and orientation of attention (29). The infrequent stimulus elicits the P3b subcomponent. P3b ERPs can differ in both amplitude and latency. Changes in amplitude are related to the attention oriented to the task (29), whereas, changes in latency are related to changes in the time to evaluate environmental stimuli (30). Changes in attention and decision making are important in the evaluation of concussed athletes and retuning them to school and sport. It was hypothesized that players with decreased $\mathrm{P} 3 \mathrm{a}$ and P3b measures would score higher on the SCAT-3.

\section{Methods}

This protocol was approved by Western University's Human Subjects Research Ethics Board.

\section{Participants}

Male participants information from the Western University (UWO) Varsity football team was collected from previous study data. This team competes in the Canadian Interuniversity Sports League (CIS) within the Ontario University Athletics Division (OUA). Only players who underwent one practice and one game in the 2015-2016 season were included, 35 participants met these criteria, ranging from age 20-23 years. These players included a number of positons and were split into subgroups accordingly; there were 14 Big Skilled (1 Quarterback, 5 Running Backs, 2 Full Backs, 6 Line Backers), 11 Small Skilled (5 Defensive Backs, 6 Wide Receivers), and 9 Big Unskilled (7 Offensive Line, 2 Defensive Line) participants.

\section{Measurements SCAT-3}

All components of the SCAT- 3 were assessed as part of this study.

\section{Symptom Evaluation}

This subcomponent of the SCAT-3 consists of a checklist of 22 common post-concussion symptoms (1). This test can be administered in four conditions; self-rated, clinician interview, self-rated with clinician monitoring or self-rated with parent input. All participants were clinically interviewed by a 
trained health care professional. Symptoms were scored on a Likert scale ranging from 0-6. Two scores were calculated, one score totaled number of symptoms with a maximum of 22 , while the other tallied symptom severity to a maximum 132 . Increases in either of these scores indicate that the individual displays more concussion related symptoms.

\section{Cognitive and Physical Evaluation}

This component of the SCAT-3 consists of four subtests; Orientation, Immediate Recall, Concentration and Delayed Recall. These tests were independently scored and summed for a total score of 31 . Increases in these scores indicate that the individual is less symptomatic, opposite that of the Symptom Evaluation.

Orientation. Participants were asked five questions; What month is it?, What is the date today?, What is the day of the week?, What year is it?, What time is it right now? (within 1 hour). Correct answers were scored for a total of five.

Immediate recall. Interviewers select one standard, five word lists and read it aloud to the subject. Participants were then required to repeat, from memory, words from the list back to the interviewer. This is repeated three times, using the same list of words, for a total score out of 15 correctly repeated words.

Concentration. Participants were read a digit span and asked to repeat it in reverse to the interviewer. Participants began by repeating three digits and progressed, if correctly repeated, to a maximum of six digits. Participants were given two chances at each span length and were scored out of 4. Following the digit span, participants were asked to repeat the months of the year in reverse order, starting with December, and were scored out of one based on completion of this task.

Delayed recall. At the end of the SCAT-3, participants were asked to recall the list of words used earlier in the Immediate Recall task, again from memory, once to be scored out of five.

\section{Modified Balance Error Scoring System (mBESS)}

The mBESS consists of three separate 20 second balance tests performed in different stances on a concrete surface. The three stances used were double leg, single leg, and tandem stance with one foot behind the other in-line. Participants stood with hands on their hips and eyes closed. Errors were scored for any of the following; hands lifted off iliac crest, opening eyes, step, stumble, or fall, moving hip into >30 degrees' abduction, lifting forefoot or heel, or remaining out of test position $>5 \mathrm{sec}$. Increases in error score show that an athlete is more symptomatic of concussion.

\section{Procedure}

\section{SCAT-3 Baseline}

Testing was conducted at Kirkley Athletic Training Center on Western University main campus. For all participants, testing was performed in a quite space. All tests were done by individuals trained in SCAT-3 testing; doctors, physiotherapists, athletic therapists, and student trainers. Testing occurred in the two days preceding training camp (Early August). The two testing periods were approximately one year apart.

\section{Electroencephalography}

Participants underwent neurophysiological testing, via the eVox System (Evoke Neuroscience, New York). Prior to the start of training camp for the 2015 and 2016 seasons, EEG tests were conducted in conjunction with the SCAT-3 testing. Participants performed three tests during baseline sessions; Eyes Open, Eyes Closed and the Oddball paradigm. For the Eyes Open task, participants stared at a computer screen for five minutes in a relaxed state. For Eyes Closed, participants sat with eyes closed for five minutes in a relaxed state. For these tasks, participants were instructed to sit as still as possible and reduce eye and face movement as much as possible, to reduce artifacts. A 10 minute Oddball paradigm was performed to complete the testing. Participants were presented one of two visual stimuli (a medium blue circle and a large blue circle) in a random series. One of the stimuli (the large blue circle) was presented infrequently (20\%). Participants were instructed to respond to this stimulus via button press. A short instructional period and practice test were completed prior to actual testing.

\section{Data Analysis}

ERP waves were obtained via 19 channel tin sensors at a rate of $250 \mathrm{~Hz}$, with linked ear ground sensors. Amplitude was measured as the difference between pre-stimulus activation and maximal amplitude. Only trials with correct responses were used in P3b analysis. Artifacts from facial muscle activation and eye movements were corrected using proprietary algorithms and visual analysis to ensure consistency. Raw data EEG data was stored in secure online data banks. Amplitude and latency changes were calculated relative to 2015 preseason 
data with positive values indicating increases. SCAT3 data was obtained from Fowler Kennedy Sport Medicine clinic as part of participants' health charts. Only Symptom Evaluation and Cognitive and Physical Evaluation scores were used in this analysis. Changes in score were calculated relative to 2015 pre-season values.

\section{Statistical Analysis}

Only participants who competed in a minimum of one practice and one game in both the 2015 and 2016 OUA football seasons were included; 35 players met these criteria. Means and standard deviations for SCAT-3 and EEG measurements in 2015, 2016 were calculated. Additionally, changes in SCAT-3 and EEG scores between these seasons were calculated-Repeated measures T-tests were performed to determine the statistical significance of the changes between 2015 and 2016 baselines in SCAT-3 and EEG measures.

\section{Results}

\section{SCAT-3}

Table 1 displays descriptive statistics for SCAT-3 performance across all groups. No measures were found to be statistically significant. However, all groups showed increases in mean values for both Number of Symptoms (Table 1; $1 \pm 4.08$ ) and Symptom Severity (Table $1 ; 1.9 \pm 6.67$ ) representing greater concussion like symptoms. Improvements were seen in Immediate Recall for both Big Skilled (Table 2; 1.5 \pm 1.2 ) and Small Skilled (Table 2; 1.09 \pm 1.5 ) groups. Big Unskilled players had the lowest immediate recall scores (Table 2; $13.6 \pm 1.7$ and 14.22 \pm 1.03 ) among the three groups. Big Skilled were the only group to show decreases in concentration scores (Table $2 ;-0.78 \pm 1.11$ ).

\section{EEG}

Descriptive statistics for all EEG measures are presented in Table 3. No significant differences were found.

P3a

P3a latency for Big Skilled players (Table 4; $39.84 \pm 64.04 \mathrm{~ms}$ ) had greater increases than Big Unskilled (Table 4; $19 \pm 27.25 \mathrm{~ms}$ ) or Small Skill (Table $4 ; 2.9 \pm 81.17 \mathrm{~ms})$. Decreases in amplitude were also see in all three groups (Table3: -5). With Small Skilled (Table 5; $-8.15 \pm 6.5 \mu \mathrm{V}$ ) having larger decreased than either Big Skilled (Table 5; $5.9 \pm 8.63 \mu \mathrm{V}$ ) or Big Unskilled (Table 5; $4.22 \pm 8.95 \mu \mathrm{V}$ ). No significant differences were found for P3a profiles between seasons.

\section{P3b}

P3b latency increased for Big Skilled (Table 6; 29.81 $\pm 66.7 \mathrm{~ms}$ ) and Big Unskilled (Table 6; $26.5 \pm 97.1 \mathrm{~ms}$ ). Decreased in latency was observed for Small Skilled players (Table 6; $-2.5 \pm 86.0 \mathrm{~ms}$ ). Average P3b amplitudes decreased for both Big Unskilled (Table $7 ;-3.58 \pm 8.12 \mu \mathrm{V}$ ) and Small Skilled (Table 7; $-4.47 \pm 10.7 \mu \mathrm{V}$ ). However, amplitudes increased on average Big Skilled players (Table 7; $1.18 \pm 4.1 \mu \mathrm{V})$. No significant differences for P3b measures were found between seasons.

\begin{tabular}{|c|c|c|c|c|c|c|}
\hline & \multicolumn{2}{|c|}{2015} & \multicolumn{2}{c|}{2016} & \multicolumn{2}{c|}{ Change } \\
\cline { 2 - 7 } & Mean & SD & Mean & SD & Mean & SD \\
\hline Symptom Number & 0.85 & 2.03 & 1.85 & 3.38 & 1.00 & 4.08 \\
\hline Symptom Severity & 1.02 & 2.41 & 2.97 & 6.04 & 1.94 & 6.67 \\
\hline Immediate Recall & 13.00 & 2.72 & 14.58 & 0.77 & 1.58 & 2.79 \\
\hline Concentration Score & 3.73 & 1.17 & 3.70 & 1.17 & -0.03 & 1.38 \\
\hline
\end{tabular}

Table 1: Descriptive statistics for SCAT-3 subtests for all players. Change was calculated relative to 2015 season scores. SCAT-3 tests were all performed by trained examiners on a single date. 


\begin{tabular}{|c|c|c|c|c|c|c|c|c|c|c|c|c|}
\hline & \multicolumn{5}{|c|}{2015} & \multicolumn{4}{c|}{2016} & \multicolumn{4}{c|}{ Change } \\
\hline & SN & SS & IR & CS & SN & SS & IR & CS & SN & SS & IR & CS \\
\hline SS AVG & 1.73 & 1.91 & 13.36 & 3.36 & 2.18 & 3.82 & 14.45 & 3.64 & 0.45 & 1.91 & 0.09 & 0.27 \\
\hline SS SD & 3.11 & 3.42 & 4.12 & 1.49 & 4.34 & 8.8 & 0.78 & 1.37 & 5.76 & 10.01 & 4.36 & 1.76 \\
\hline BS AVG & 0.36 & 0.36 & 13.43 & 3.86 & 1.5 & 2.14 & 14.93 & 4.07 & 1.14 & 1.79 & 1.5 & 0.21 \\
\hline BS SD & 0.89 & 0.89 & 1.24 & 0.99 & 2.77 & 3.62 & 0.26 & 0.96 & 2.87 & 3.76 & 1.18 & 1.01 \\
\hline BU AVG & 0.56 & 1 & 13.6 & 4 & 2 & 3.22 & 14.22 & 3.22 & 1.44 & 2.22 & 1.11 & -0.78 \\
\hline BU SD & 1.07 & 2.21 & 1.7 & 0.82 & 2.83 & 4.59 & 1.03 & 1.03 & 2.99 & 4.87 & 1.91 & 1.03 \\
\hline
\end{tabular}

Table 2: Descriptive statistics for SCAT-3 divided into subgroups. Change was calculated relative to the 2015 season scores. (SN- Symptom Number, SS-Symptom Severity, IR- Immediate Recall, CS-Concentration Scores)

\begin{tabular}{|c|c|c|c|c|c|c|}
\hline & \multicolumn{2}{|c|}{2015} & \multicolumn{2}{c|}{2016} & \multicolumn{2}{c|}{ Change } \\
\cline { 2 - 7 } & Mean & SD & Mean & SD & Mean & SD \\
\hline P3a Latency & 400.94 & 40.64 & 421.43 & 62.69 & 28.82 & 27.81 \\
\hline P3a Amplitude & 24.26 & 7.14 & 17.2 & 8.36 & -6.78 & 7.59 \\
\hline P3b Latency & 421.74 & 165.26 & 504.77 & 53.52 & -26 & 77.76 \\
\hline P3b Amplitude & 17.9 & 6.76 & 15.94 & 5.66 & -1.23 & 4.84 \\
\hline
\end{tabular}

Table 3: Descriptive statistics for changes in EEG readings for all participants. Amplitudes are measured in microvolts $(\mu \mathrm{V})$. Latencies are measured in milliseconds (ms). Changes are relative to 2015 season data.

\begin{tabular}{|c|c|c|c|c|c|c|}
\hline \multirow{2}{*}{} & \multicolumn{2}{|c|}{2015} & \multicolumn{2}{c|}{2016} & \multicolumn{2}{c|}{ Change } \\
\cline { 2 - 7 } & Mean & SD & Mean & SD & Mean & SD \\
\hline Small Skilled & 403.21 & 170.51 & 400.71 & 44.13 & -2.5 & 86.06 \\
\hline Big Skilled & 379.03 & 227.83 & 514.8 & 59.14 & 29.81 & 66.7 \\
\hline Big Unskilled & 456.88 & 70.74 & 480 & 52.26 & 26.5 & 97.13 \\
\hline Total & $\mathbf{4 1 3 . 0 4}$ & $\mathbf{1 5 6 . 3 6}$ & $\mathbf{4 6 5 . 1 7}$ & $\mathbf{5 1 . 8 4}$ & $\mathbf{1 7 . 9 4}$ & $\mathbf{8 3 . 3}$ \\
\hline
\end{tabular}

Table 4: Descriptive statistics for P3a Latency. Latencies were measures in milliseconds (ms). Changes are relative to the 2015 season. 


\begin{tabular}{|c|c|c|c|c|c|c|}
\hline & \multicolumn{2}{|c|}{2015} & \multicolumn{2}{c|}{2016} & \multicolumn{2}{c|}{ Change } \\
\cline { 2 - 7 } & Mean & SD & Mean & SD & Mean & SD \\
\hline Small Skilled & 27.13 & 8.63 & 15.89 & 8.54 & -8.15 & 6.5 \\
\hline Big Skilled & 24.01 & 6.16 & 17.39 & 7.32 & -5.92 & 8.63 \\
\hline Big Unskilled & 22.04 & 5.95 & 18.68 & 9.36 & -4.22 & 8.95 \\
\hline Total & $\mathbf{2 4 . 3 9}$ & $\mathbf{6 . 9 1}$ & $\mathbf{1 7 . 3 2}$ & $\mathbf{8 . 4 1}$ & $\mathbf{- 6 . 1}$ & $\mathbf{8 . 0 3}$ \\
\hline
\end{tabular}

Table 5: Descriptive statistics for P3a amplitude. Amplitudes were measures in microvolts $(\mu \mathrm{V})$. Changes are relative to the 2015 season.

\begin{tabular}{|c|c|c|c|c|c|c|}
\hline \multirow{2}{*}{} & \multicolumn{2}{|c|}{2015} & \multicolumn{2}{c|}{2016} & \multicolumn{2}{c|}{ Change } \\
\cline { 2 - 7 } & Mean & SD & Mean & SD & Mean & SD \\
\hline Small Skilled & 397.09 & 34.45 & 400 & 81.4 & 2.9 & 81.17 \\
\hline Big Skilled & 404.85 & 48.52 & 443.23 & 53.82 & 39.84 & 64.04 \\
\hline Big Unskilled & 399.55 & 32.9 & 415.5 & 21.48 & 19 & 27.25 \\
\hline Total & $\mathbf{4 0 0 . 5}$ & $\mathbf{3 8 . 6 2}$ & $\mathbf{4 1 9 . 5 8}$ & $\mathbf{5 2 . 2 3}$ & $\mathbf{2 0 . 5 8}$ & $\mathbf{5 7 . 4 9}$ \\
\hline
\end{tabular}

Table 6: Descriptive statistics for P3b latency divided by subgroup. Latencies are measured in milliseconds (ms). Changes relative to the 2015 season.

\begin{tabular}{|c|c|c|c|c|c|c|}
\hline & \multicolumn{2}{|c|}{2015} & \multicolumn{2}{c|}{2016} & \multicolumn{2}{c|}{ Change } \\
\cline { 2 - 7 } & Mean & SD & Mean & SD & Mean & SD \\
\hline Small Skilled & 20.97 & 9.021 & 15.91 & 5.66 & -4.47 & 10.76 \\
\hline Big Skilled & 15.08 & 2.33 & 15.87 & 5.43 & 1.18 & 4.15 \\
\hline Big Unskilled & 18.622 & 6.67 & 16.11 & 6.013 & -3.58 & 8.12 \\
\hline Total & $\mathbf{1 8 . 2 2 4}$ & $\mathbf{6 . 0 0 7}$ & $\mathbf{1 5 . 9 6}$ & $\mathbf{5 . 7 0 1}$ & $\mathbf{- 2 . 2 9}$ & $\mathbf{7 . 6 8}$ \\
\hline
\end{tabular}

Table 7: Descriptive statistics for P3b amplitude. Changes are relative to the 2015 season. Amplitudes were measures in microvolts $(\mu \mathrm{V})$ 
(a) - Changes In P3b Amplitude and Symptom Score

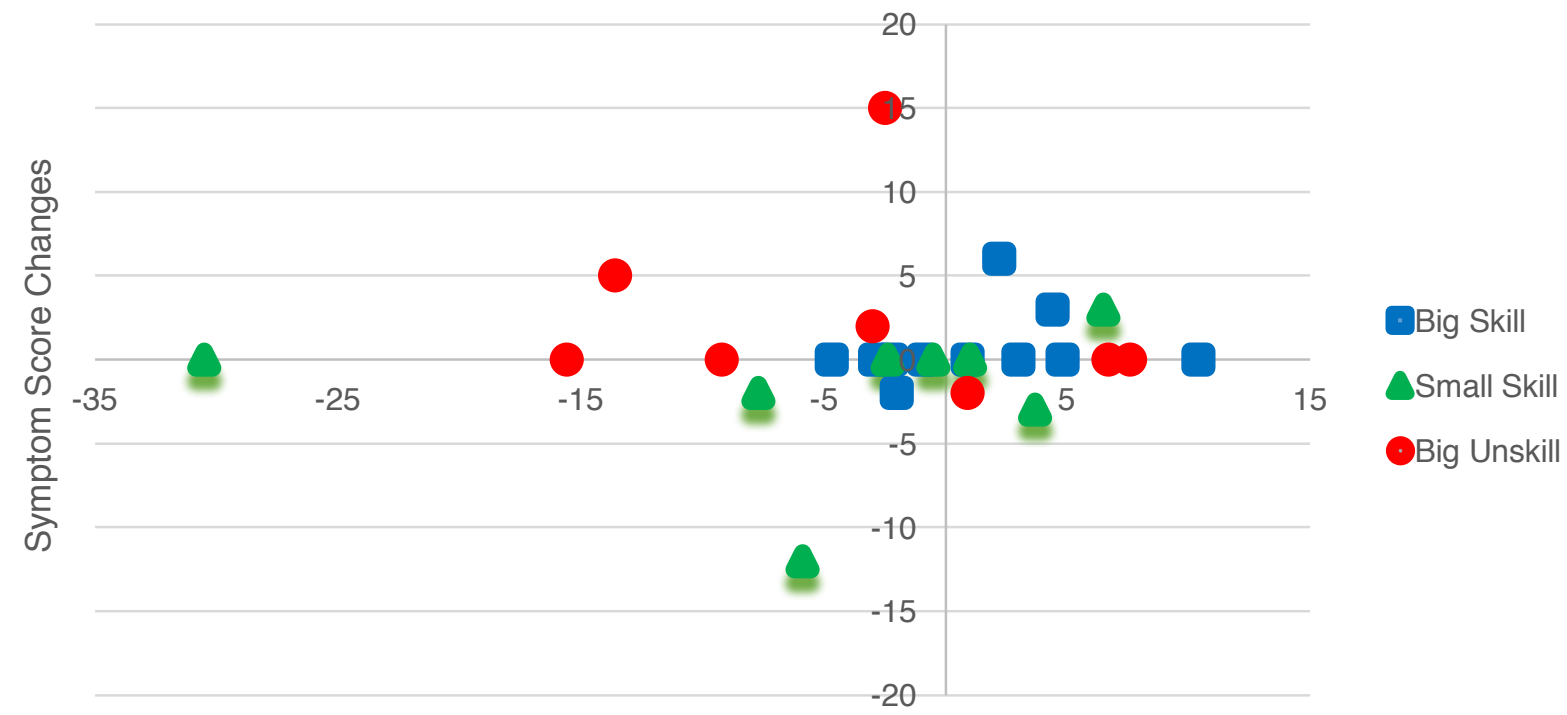

Change in P3b Amplitude $(\mu \mathrm{V})$

(b) - Changes In P3b Amplitude and Symptom Score

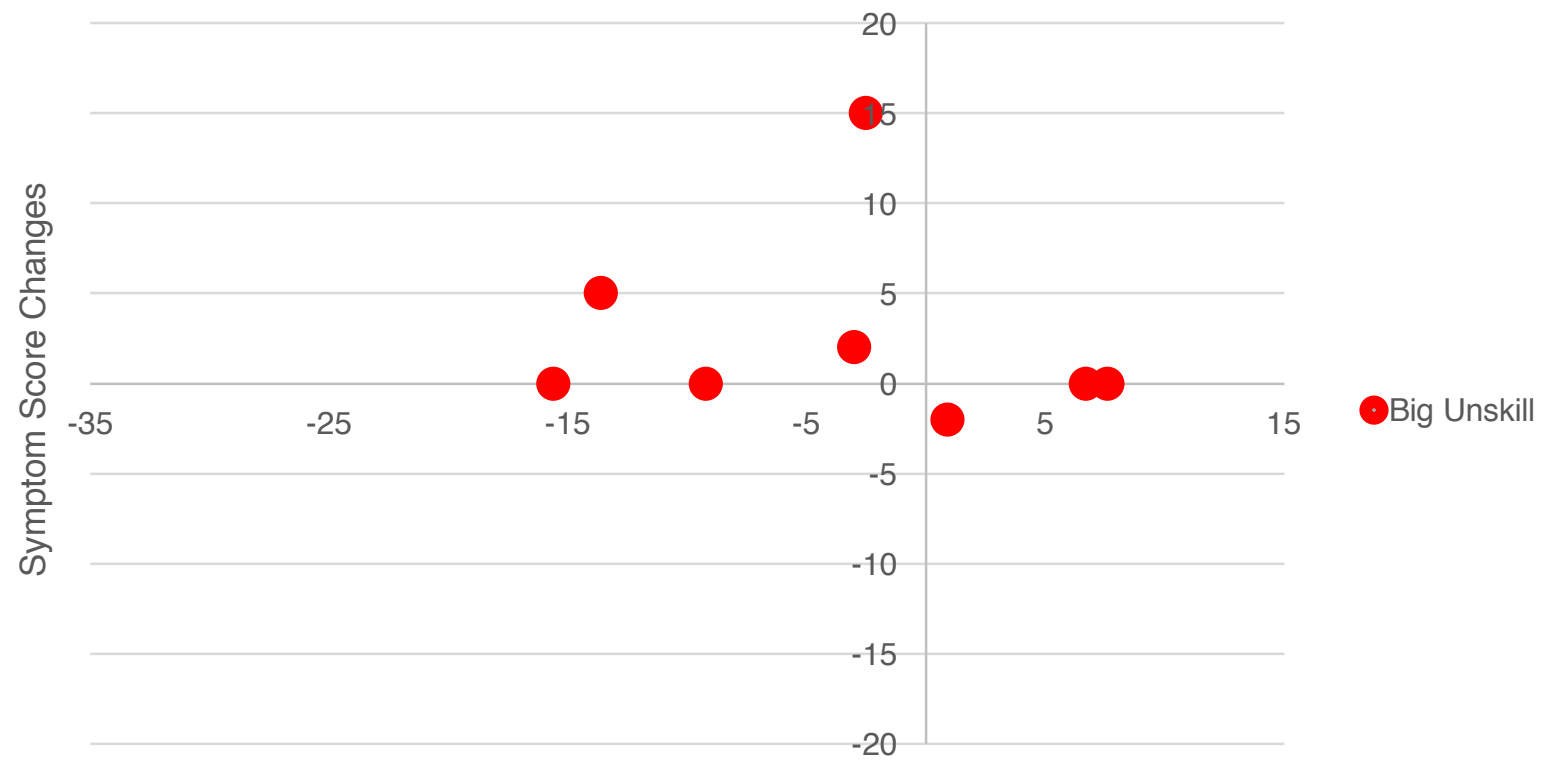

Change in P3b Amplitude $(\mu \mathrm{V})$

Figure 1: (a) X-axis represents changes in P3a amplitudes in microvolts $(\mu \mathrm{V})$, positive values indicate increased amplitude. $Y$-axis shows changes in symptoms severity with positive values indicating more symptom related concussions. (b) Same as above isolated for big unskilled players 
(a) - Changes in P3b Amplitude and Concentration Score

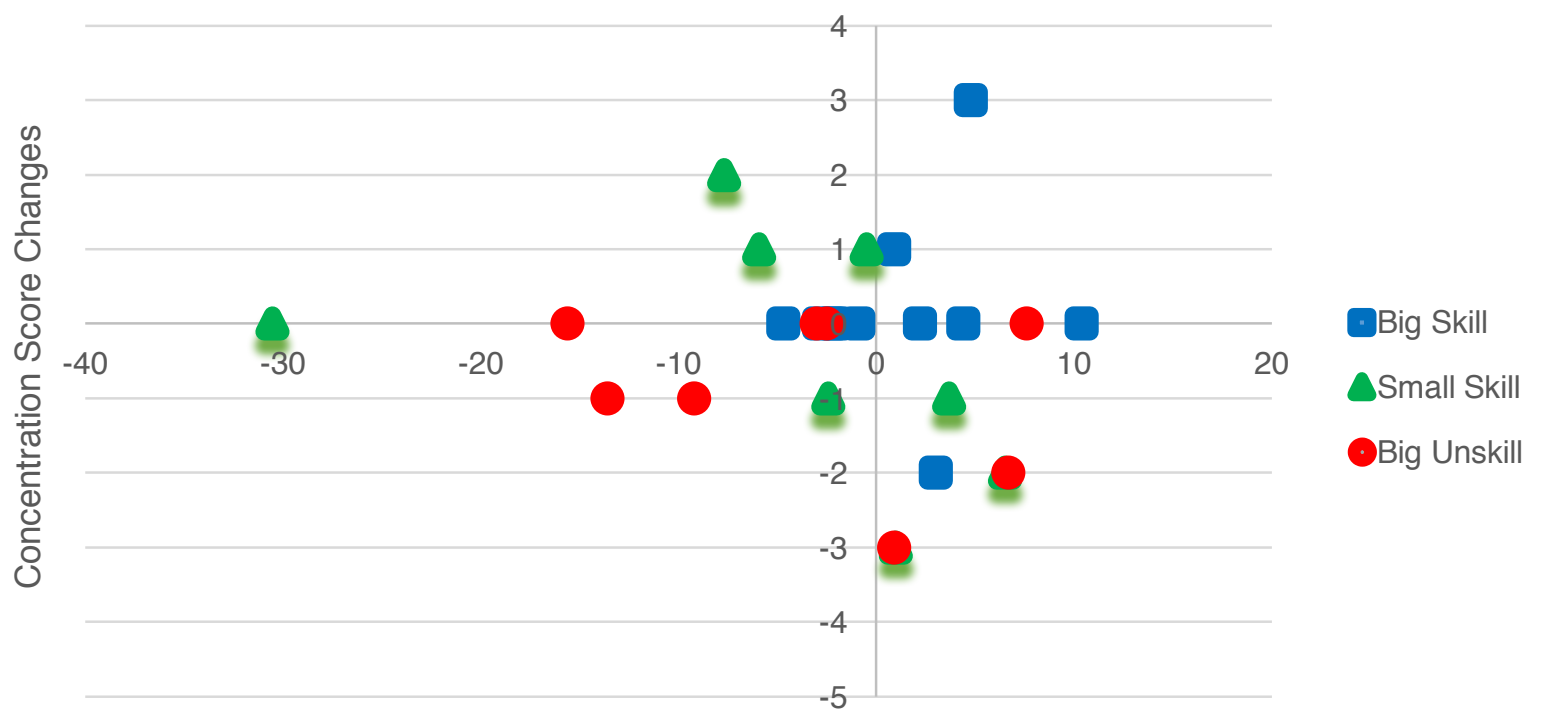

Change in P3b Amplitude $(\mu \mathrm{V})$

(b) - Changes in P3b Amplitude and Concentration Score

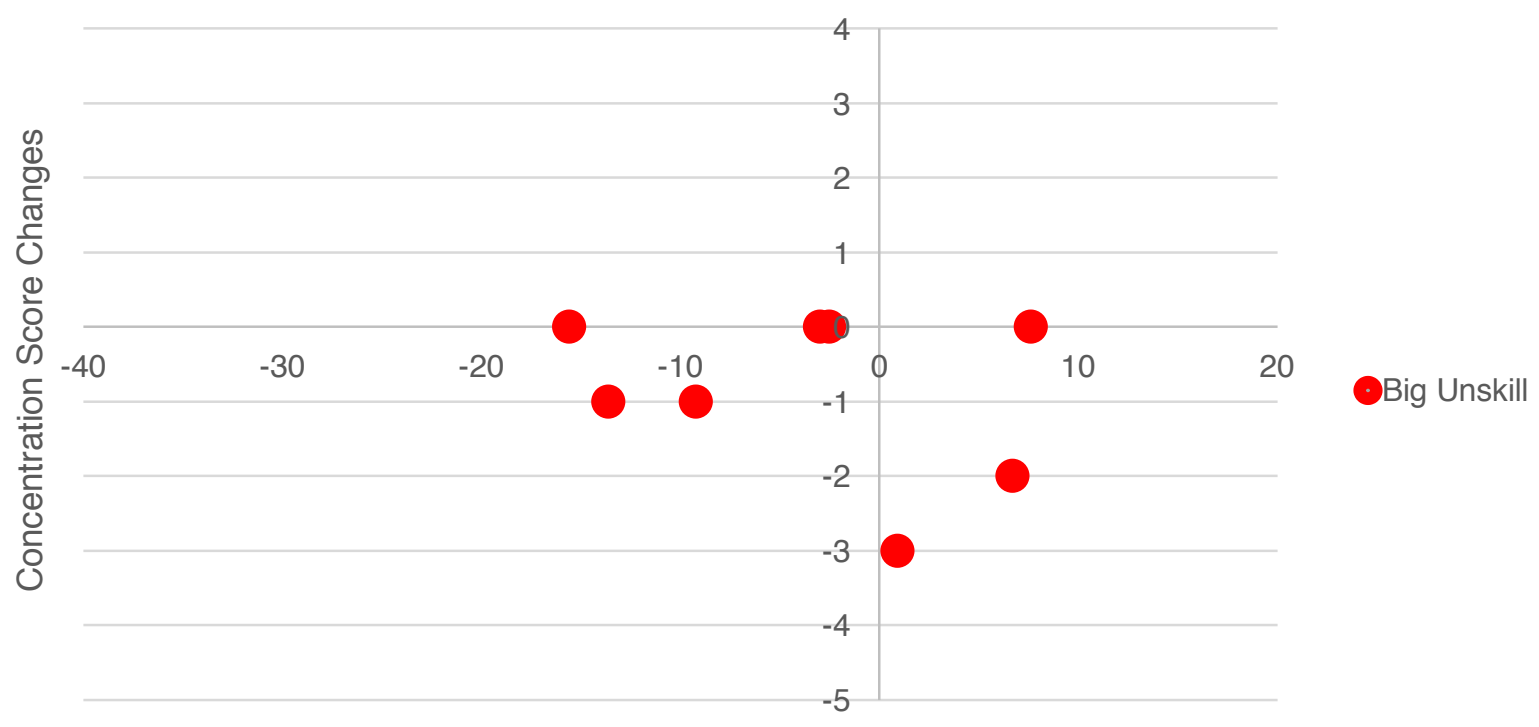

Change in P3b Amplitude $(\mu \mathrm{V})$

Figure 2: (a) X-axis represents changes in P3a amplitudes in microvolts $(\mu \mathrm{V})$, positive values indicate increased amplitude. Y-axis shows changes in Concentration score with decreased scores representing greater symptom severity. (b) Same as above isolated for Big Unskilled. 


\section{Discussion}

The purpose of this study was to examine the effects of accumulated impacts on Canadian University football players, through SCAT-3 and EEG testing. It was hypothesized that players with decreased EEG measurements would be more symptomatic on SCAT-3. However, no significant differences or group effects were found.

Mean SCAT-3 scores increased for Symptom Number and Symptom Severity. These changes represent increased presentation of concussion symptoms. This differs from previous research that found no change or improvements in non-injured athletes (31). Big Unskilled players were the only group to show decrease in concentration scores $(-.77 \pm 1.03)$. Big Unskilled players are thought to receive the greatest number of impacts in a season (12). One point decreases in the Cognitive and Physical Evaluation show $94 \%$ sensitivity and $76 \%$ specificity in diagnosing concussion (20). These changes would categorize some players as 'injured' via reliable change indices (32). SCAT-3 has been studied and validated in athletes $(1,33,34)$ therefore; these changes in scores are meaningful for the sample studied.

The P3a component of the P300 ERP is thought to relate to the orientation of attention (35). On average, all groups showed increased in $\mathrm{P} 3 \mathrm{a}$ amplitude. This contradicts findings of no change in P3a amplitude following concussion in other studies (23). These changes eluded to an increase in attention needed to focus on the relevant task. P3a exhibits a frontal lobe scalp distribution, and lesion studies support frontal lobe origin (36). The changes in P3a amplitude found in the present study suggest abnormal frontal lobe function. Deficits, primarily in the dorsolateral prefrontal cortex, have been found post-concussion (37-40). Decreases in amplitude were smallest for Small Skilled players, which are the group found for have the smallest number of impacts (12). This contradicts the hypothesis of larger deficits in high hit players. However, latency had the largest increase for Big Unskilled players who average the most impacts (12).

The P3b subcomponent is theorized to be related to allocation of attentional recourses and updating context of working memory (29). The findings of decreases in amplitude support previous research $(41,42)$. P3b amplitude is thought to relate to the allocation of attentional recourses for a given task $(43,44)$. It has been theorized that P3b is related to an inhibition of irrelevant stimulus (35). Decreases in amplitude seen in this study could relate to a decreased ability to inhibit irrelevant cues. P3b has been related to working memory, which has hippocampal origins (45-47). P3b latency is related to stimulus detection, classification and evaluation (48-51). Our results support previous research that asymptomatic athletes show increased P3a latency post impact (42). With participants showing decreases in $\mathrm{Pb} 3$ measures on average, further investigation into hippocampal deficits and $\mathrm{SCl}$ is warranted.

No significant differences were found between changes in SCAT-3 and EEG (Figure 1a). However, trends can be observed between decreased in P3b amplitude and Symptom Severity for Big Unskilled players (Figure 1b). All Big Unskilled players who showed a deficit in P3b amplitude also showed an increase in Symptom Severity Scores. Big Unskilled players also demonstrate trends between decreased P3b amplitude and decreases in Concertation Score (Figure $2 b$ ). These both support the hypothesis' that deficits seen on EEG would manifest as symptom presentation and these effects would be more significant in high impact groups.

The present study limited in its sample size. Additionally, the high variability of the data meant that it was unlikely to achieve statistically significant results. Although the purpose of this study was to observe the effects of sub-concussive impacts, athletes may have experienced undiagnosed concussions. Although the SCAT-3 has been shown to valid and have high interrater reliability (32), inconsistencies in testing between clinicians are possible. Athletes have been shown to purposely fabricate baseline scores to avoid removal from play post-concussion $(53,53)$. Additionally, player impact profiles were assumed from previous data and may not be true representations of the impacts that occurred during the season. Finally, participants were required to compete in a minimum of one game and practice for inclusion leaving the possibility of much fewer impacts in single game players.

\section{Conclusion}

In summary, these results show that University football players show neurophysiologic deficits from accumulated head impacts during their football season. These deficits are not resolved over an off-season of rest. This is important because these deficits may accumulate each successive season. Over a football players career, these accumulations may cause noticeable changes. However, due to their slow onset, these changes are harder for family, coaches, and medical professions 
to identify. This brings merit to EEG measurements, due to their sensitivity to small changes in function, being incorporated in evaluation of player health. The SCAT-3 is less sensitive to minor changes, but still critical acutely in the diagnosis of concussion. Future research should investigate the effects of subconcussive impacts over multiple seasons for longitudinal observation.

\section{Acknowledgements}

This project was completed as part of the course requirements for Kinesiology 4520, Clinical Biomechanics. I would like to thank Dr. Jim Dickey and Jeff Brooks. Without their assistance and expertise this project would not have been possible. Additional thanks to Dr. James Thompson and Evoke neuroscience for the use of their EEG equipment.

\section{References}

1. McCrory $P$, Meeuwisse WH, Aubry M, Cantu B, Dvořák J, Echemendia RJ, Engebretsen L, Johnston K, Kutcher JS, Raftery M, Sills A. Consensus statement on concussion in sport: the 4th International Conference on Concussion in Sport held in Zurich, November 2012. Br J Sports Med. 2013 Apr 1;47(5):250-8. DOI: 10.1016/j.ptsp.2013.03.002

2. Zasler ND, Katz DI, Zafonte RD, editors. Brain injury medicine: principles and practice. Demos Medical Publishing; 2012 Aug 27.

3. McCrea M, Guskiewicz KM, Marshall SW, Barr W, Randolph C, Cantu RC, Onate JA, Yang J, Kelly JP. Acute effects and recovery time following concussion in collegiate football players: the NCAA Concussion Study. Jama. 2003 Nov 19;290(19):2556-63. DOI: 10.1001/jama.290.19.2556

4. Bleiberg J, Cernich AN, Cameron K, Sun W, Peck K, Ecklund J, Reeves D, Uhorchak J, Sparling MB, Warden DL. Duration of cognitive impairment after sports concussion. Neurosurgery. 2004 May 1;54(5):1073-80. DOI: 10.1227/01.NEU.0000118820.33396.6A

5. McKee AC, Cantu RC, Nowinski CJ, Hedley-Whyte ET, Gavett BE, Budson AE, Santini VE, Lee HS, Kubilus CA, Stern RA. Chronic traumatic encephalopathy in athletes: progressive tauopathy after repetitive head injury. Journal of Neuropathology \& Experimental Neurology. 2009 Jul 1;68(7):709-35.DOI:10.1097/NEN.0b013e3181a9d503

6. Omalu B, Bailes J, Hamilton RL, Kamboh MI, Hammers J, Case M, Fitzsimmons R. Emerging histomorphologic phenotypes of chronic traumatic encephalopathy in American athletes.Neurosurgery.2011Feb24;69(1)17383.DOI:10.1227/NEU.0b013e318212bc7b

7. McKee AC, Stein TD, Nowinski CJ, Stern RA, Daneshvar DH, Alvarez VE, Lee HS, Hall G, Wojtowicz SM, Baugh CM, Riley DO. The spectrum of disease in chronic traumatic encephalopathy. Brain. 2013 Jan 1;136(1):43-64. DOI: 10.1093/brain/aws307

8. Hazrati LN, Tartaglia MC, Diamandis P, Davis KD, Green RE, Wennberg R, Wong JC, Ezerins L, Tator $\mathrm{CH}$. Absence of chronic traumatic encephalopathy in retired football players with multiple concussions and neurological symptomatology. Frontiers in human neuroscience. 2013;7. DOI: 10.3389/fnhum.2013.00222

9. Pellman EJ, Viano DC, Tucker AM, Casson IR. Concussion in professional football: Location and direction of helmet impacts-Part 2. Neurosurgery. 2003 Dec 1;53(6):1328-41. DOI: 10.1227/01.NEU.0000093499.20604.21

10. Baugh CM, Stamm JM, Riley DO, Gavett BE, Shenton ME, Lin A, Nowinski CJ, Cantu RC, McKee AC, Stern RA. Chronic traumatic encephalopathy: neurodegeneration following repetitive concussive and subconcussive brain trauma. Brain imaging and behavior. 2012 Jun 1;6(2):244-54. DOI: 10.1007/s11682-012-9164-5

11. Bazarian JJ, Zhu T, Zhong J, Janigro D, Rozen E, Roberts A, Javien $H$, Merchant-Borna K, Abar B, Blackman EG. Persistent, long-term cerebral white matter changes after sports-related repetitive head impacts. PLoS One. 2014 Apr 16;9(4):e94734. OI: 10.1371/journal.pone.0094734

12. Brooks JS. The use of $P 3 b$ as an indicator of neurophysiologic change from subconcussive impacts in football players.

13. Stern RA, Riley DO, Daneshvar DH, Nowinski CJ, Cantu RC, McKee AC. Long-term consequences of repetitive brain trauma: chronic traumatic encephalopathy. Pm\&r. 2011 Oct 31;3(10):S460-7. DOI: 10.1016/j.pmrj.2011.08.008

14. Covassin T, Elbin III R, Stiller-Ostrowski JL. Current sportrelated concussion teaching and clinical practices of sports medicine professionals. Journal of athletic training. 2009 Jul;44(4):400-4. DOI: 10.4085/1062-6050-44.4.400

15. Merkel DL, Molony Jr JT. Medical sports injuries in the youth athlete: emergency management. International journal of sports physical therapy. $2012 \mathrm{Apr} ; 7(2): 242$.

16. Okonkwo DO, Tempel ZJ, Maroon J. Sideline assessment tools for the evaluation of concussion in athletes: a review. Neurosurgery. 2014 Oct 1;75(suppl_4):S82-95. DOI: 10.1227/NEU.0000000000000493

17. Broglio SP, Ferrara MS, Piland SG, Anderson RB. Concussion history is not a predictor of computerised neurocognitive performance. British Journal of Sports Medicine. 2006 Sep 1;40(9):802-5. DOI: 10.1136/bjsm.2006.028019

18. Fischer C, Morlet D, Giard MH. Mismatch negativity and N100 in comatose patients. Audiology and Neurotology. 2000;5(34):192-7. DOI: 10.1159/000013880

19. Brickman AM, Paul RH, Cohen RA, Williams LM, MacGregor KL, Jefferson AL, Tate DF, Gunstad J, Gordon E. Category and letter verbal fluency across the adult lifespan: relationship to EEG theta power. Archives of Clinical Neuropsychology. 2005 Jul 31;20(5):561-73. DOI: 10.1016/j.acn.2004.12.006

20. Daltrozzo J, Schön D. Conceptual processing in music as revealed by $\mathrm{N} 400$ effects on words and musical targets. Journal of Cognitive Neuroscience. 2009 Oct;21(10):1882-92. DOI: $10.1162 /$ jocn.2009.21113

21. Luck SJ. An introduction to the event-related potential technique. MIT press; 2014 Jun 20.

22. Giacino JT, Fins JJ, Laureys S, Schiff ND. Disorders of consciousness after acquired brain injury: the state of the science. Nature Reviews Neurology. 2014 Feb 1;10(2):99114. DOI: $10.1038 / n$ neurol.2013.279

23. Broglio SP, Pontifex MB, O'Connor $\mathrm{P}$, Hillman $\mathrm{CH}$. The persistent effects of concussion on neuroelectric indices of attention. Journal of neurotrauma. 2009 Sep 1;26(9):1463-70. DOI: $10.1089 /$ neu.2008.0766

24. Donchin E, Coles MG. Is the P300 component a manifestation of context updating?. Behavioral and brain sciences. 1988 Sep;11(3):357-74. DOI: 10.1142/S0219635212500215

25. Courjon J. Traumatic disorders. Handbook of electroencephalography and clinical neurophysiology. 1972;14:8-95. DOI 10.1155/1998/728634

26. Gaetz M, Bernstein DM. The current status of electrophysiologic procedures for the assessment of mild traumatic brain injury. The Journal of head trauma rehabilitation. 2001 Aug 1;16(4):386-405.

27. Sutton S, Braren M, Zubin J, John ER. Evoked-potential 
correlates of stimulus uncertainty. Science. 1965 Nov 26;150(3700):1187-8.

28. Picton TW. The P300 wave of the human event-related potential. Journal of clinical neurophysiology. 1992 Oct $1 ; 9(4): 456-79$

29. Kramer AF, Strayer DL. Assessing the development of automatic processing: an application of dual-task and eventrelated brain potential methodologies. Biological psychology. 1988 Jun 30;26(1):231-67.

30. Kutas M, Dale A. Electrical and magnetic readings of mental functions. Cognitive neuroscience. 1997:197-242.

31. Miller JR, Adamson GJ, Pink MM, Sweet JC. Comparison of preseason, midseason, and postseason neurocognitive scores in uninjured collegiate football players. The American journal of sports medicine. 2007 Aug;35(8):1284-8. DOI: 10.1177/0363546507300261

32. McLeod TC, Barr WB, McCrea M, Guskiewicz KM. Psychometric and measurement properties of concussion assessment tools in youth sports. Journal of athletic training. 2006 Oct;41(4):399.

33. Hänninen T, Tuominen M, Parkkari J, Vartiainen M, Öhman J, Iverson GL, Luoto TM. Sport concussion assessment tool-3rd edition-normative reference values for professional ice hockey players. Journal of Science and Medicine in Sport. 2016 Aug 31;19(8):636-41. DOI: 10.1016/j.jsams.2015.08.005

34. Snyder AR, Bauer RM, Health IMPACTS for Florida Network. A normative study of the sport concussion assessment tool (SCAT2) in children and adolescents. The Clinical Neuropsychologist. 2014 Oct 3;28(7):1091-103. DOI: 10.1080/13854046.2014.952667

35. Polich J. Updating P300: an integrative theory of P3a and P3b. Clinical neurophysiology. 2007 Oct $31 ; 118(10): 2128-48$. DOI: 10.1016/j.clinph.2007.04.019

36. Knight RT. Decreased response to novel stimuli after prefrontal lesions in man. Electroencephalography and Clinical Neurophysiology/Evoked Potentials Section. 1984 Feb 29;59(1):9-20.

37. Levin $\mathrm{H}$, Kraus MF. The frontal lobes and traumatic brain injury. Journal of Neuropsychiatry and Clinical Neurosciences. 1994 Jan;6:443. DOI: 10.1176/jnp.6.4.443

38. Chen JK, Johnston KM, Frey S, Petrides M, Worsley K, Ptito A. Functional abnormalities in symptomatic concussed athletes: an fMRI study. Neuroimage. 2004 May 31;22(1):6882. DOI: 10.1016/j.neuroimage.2003.12.032

39. Cohen BA, Inglese M, Rusinek H, Babb JS, Grossman RI, Gonen O. Proton MR spectroscopy and MRI-volumetry in mild traumatic brain injury. American Journal of Neuroradiology. 2007 May 1;28(5):907-13.

40. Chen JK, Johnston KM, Collie A, McCrory P, Ptito A. A validation of the post concussion symptom scale in the assessment of complex concussion using cognitive testing and functional MRI. Journal of Neurology, Neurosurgery \& Psychiatry. 2007 Nov 1;78(11):1231-8. DOI: 10.1136/jnnp.2006.110395
41. Dupuis F, Johnston KM, Lavoie M, Lepore F, Lassonde M. Concussions in athletes produce brain dysfunction as revealed by event-related potentials. Neuroreport. $2000 \mathrm{Dec}$ 18;11(18):4087-92.

42. Gosselin N, Thériault M, Leclerc S, Montplaisir J, Lassonde M. Neurophysiological anomalies in symptomatic and asymptomatic concussed athletes. Neurosurgery. 2006 Jun $1 ; 58(6): 1151-61$.

DOI: 10.1227/01.NEU.0000215953.44097.FA

43. Polich J. Task difficulty, probability, and inter-stimulus interval as determinants of P300 from auditory stimuli. Electroencephalography and Clinical Neurophysiology/Evoked Potentials Section. 1987 Jul 31;68(4):311-20.

44. Katayama JI, Polich J. P300 from one-, two-, and threestimulus auditory paradigms. International Journal of Psychophysiology. 1996 Sep 30;23(1):33-40. DOI: 10.1016/0167-8760(96)00030-X

45. Polich J, Criado JR. Neuropsychology and neuropharmacology of P3a and P3b. International Journal of Psychophysiology. 2006 May 31;60(2):172-85. DOI: 10.1016/j.jpsycho.2005.12.012

46. Ranganath C, D'Esposito M. Medial temporal lobe activity associated with active maintenance of novel information. Neuron. 2001 Sep 13;31(5):865-73. DOI: 10.1016/S08966273(01)00411-1

47. Fuentemilla L, Penny WD, Cashdollar N, Bunzeck N, Düzel E. Theta-coupled periodic replay in working memory. Current Biology. $\quad 2010 \quad$ Apr 13;20(7):606-12. DOI: 10.1016/j.cub.2010.01.057

48. Duncan-Johnson CC. P300 latency: A new metric of information processing. Psychophysiology. 1981 May.

49. Kutas M, McCarthy G, Donchin E. Augmenting mental chronometry: the P300 as a measure of stimulus evaluation time. Science. 1977 Aug 19;197(4305):792-5.

50. Comerchero MD, Polich J. P3a and P3b from typical auditory and visual stimuli. Clinical Neurophysiology. 1999 Jan 31:110(1):24-30. DOI: 10.1016/S0168-5597(98)00033-1

51. Magliero A, Bashore TR, Coles MG, Donchin E. On the dependence of P300 latency on stimulus evaluation processes. Psychophysiology. 1984 Mar 1;21(2):171-86. DOI: 10.1111/j.1469-8986.1984.tb00201.x

52. Hunt TN, Ferrara MS, Miller LS, Macciocchi S. The effect of effort on baseline neuropsychological test scores in high school football athletes. Archives of Clinical Neuropsychology. 2007 Jun 30;22(5):615-21. DOI: 10.1016/j.acn.2007.04.005

53. Schatz $P$, Glatts $C$. "Sandbagging" baseline test performance on ImPACT, without detection, is more difficult than it appears. Archives of Clinical Neuropsychology. 2013 Feb 11;28(3):23644. DOI:10.1093/arclin/act009 